Note

\title{
Similarity in the Structure of tetD-Carrying Mobile Genetic Elements in Bacterial Strains of Different Genera Isolated from Cultured Yellowtail
}

\author{
MANABU FURUSHITA*, HIROSHI AKAGI, AZUSA KANEOKA, TOSHIMICHI MAEDA, \\ TSUBASA FUKUDA, RYOHEI TATSUNO, AND TSUNEO SHIBA
}

\author{
Department of Food Science and Technology, National Fisheries Univ., \\ Nagata-honmachi, Shimonoseki, Yamaguchi 759-6595, Japan
}

Received 4 December, 2015/Accepted 1 April, 2016

\begin{abstract}
Structure analysis was performed on the antibiotic-resistance-gene region of conjugative plasmids of four fish farm bacteria.

The kanamycin resistance gene, IS26, and tetracycline resistance gene $(\operatorname{tet} A(D))$ were flanked by two IS26s in opposite orientation in Citrobacter sp. TA3 and TA6, and Alteromonas sp. TA55 from fish farm A. IS26-Inner was disrupted with ISRSB101. The chloramphenicol resistance gene, IS26 and tet $A(D)$ were flanked by two IS26s in direct orientation in Salmonella sp. TC67 from farm C. Structures of $\operatorname{tet} A(D)$ and IS26 were identical among the four bacteria, but there was no insertion within the IS26-Inner of Salmonella sp. TC67. Horizontal gene transfer between the strains of two different genera in fish farm A was suggested by the structure homologies of mobile genetic elements and antibiotic resistance genes.
\end{abstract}

Key words : Tetracycline resistant gene / Transferable plasmid / Mobile elements / Cultured yellowtail / Fish farm bacteria.

Frequent use of antibiotics in fish farms is concerned with the increased antibiotic resistance of bacteria. Since many antibiotic resistance genes are encoded by transferable elements including plasmids and transposons, cultured fish may serve as a vehicle for transmission of antibiotic resistance to bacteria that are commensal or pathogenic to humans (Rhodes et al., 2000). In our previous study at three different fish farms (A, B, and C) located in the southern part of Japan (Furushita et al., 2003), we confirmed the presence of conjugative plasmids conferring the resistance to tetracycline, kanamycin and chloramphenicol in four bacteria of three different genera, isolated from cultured yellowtails collected at fish farm $A$ and $C$. Each fish farm was separated from each other by over $100 \mathrm{~km}$ and no reliable data on antibiotic use were obtained from the fish farmers (Furushita et al., 2003). The tetracycline-resistance gene was identified as tetA $(D)$ (Allard et al., 1993). Since multi-drug resistance is usually encoded

* Corresponding author. Tel: +81-832-86-5111, Fax: +81-83286-7434, E-mail : furushita (a)fish-u.ac.jp in mobile genetic elements such as a transposon (Chalmers et al., 2000; Furushita et al., 2011), and transferred across cells by conjugative plasmids in the marine environment (Dahlberg et al., 2000; Dahlberg et al., 1997; Kim and Aoki, 1993; Sandaa and Enger, 1994), we analyzed the structure of the plasmids, and determined the nucleotide sequence of the drug-resistance-gene region.

Plasmids were extracted by the method of Kado and Liu (1981), dissolved in $9 \mathrm{ml}$ TES buffer (0.05 M Tris- $\mathrm{HCl}$ [pH 8.0], $0.05 \mathrm{M} \mathrm{NaCl}, 5 \mathrm{mM}$ EDTA) (Yano and Nishi, 1980) containing $9 \mathrm{~g}$ of $\mathrm{CsCl}_{2}$ and $540 \mu \mathrm{l}$ of $10 \%$ ethidium bromide solution, and collected by centrifugation at $343,000 \mathrm{~g}$ for $4 \mathrm{~h}$ with a NVT65.2 rotor (Beckman, USA). The purified plasmids were digested with Hindlll or Sall, and applied to agarose-gel electrophoresis. A DNA probe for the tetA $(D)$ was prepared by using the PCR method (Furushita et al., 2003). The probe was labeled with alkaline phosphatase by using the AlkPhos direct labeling kit (Amersham Biosciences, $\mathrm{NJ}$ ). Southern hybridization was carried out according to the manufacturer's instruction, and the results are 
$\begin{array}{llllllllll}1 & 2 & 3 & 4 & 5 & 1 & 2 & 3 & 4 & 5\end{array}$

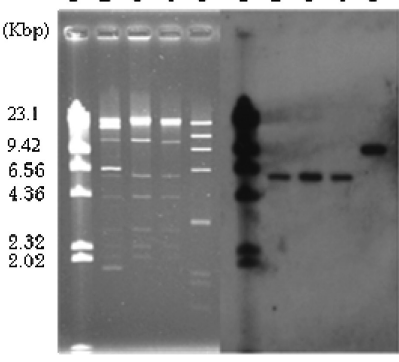

Hind III $\begin{array}{llllllllll}1 & 2 & 3 & 4 & 5 & 1 & 2 & 3 & 4 & 5\end{array}$

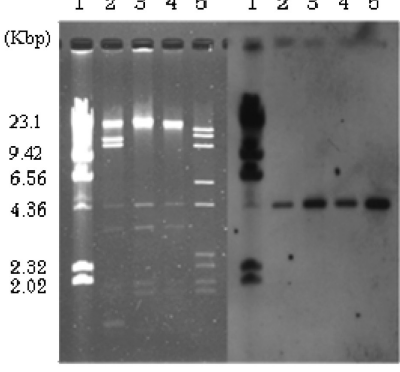

Sol I

FIG. 1. Restriction enzyme digestion and Southern hybridization patterns of tetA(D)-plasmids digested with Hindlll or Sall. Hybridization was done with a PCR-amplified tetD probe (see text). Lane 1, $\lambda$ /HindllI DNA; Lane 2, Citrobacter sp. TA3; Lane 3, Citrobacter sp. TA6; Lane 4, Alteromonas sp. TA55; Lane 5, Salmonella sp. TC67.

A

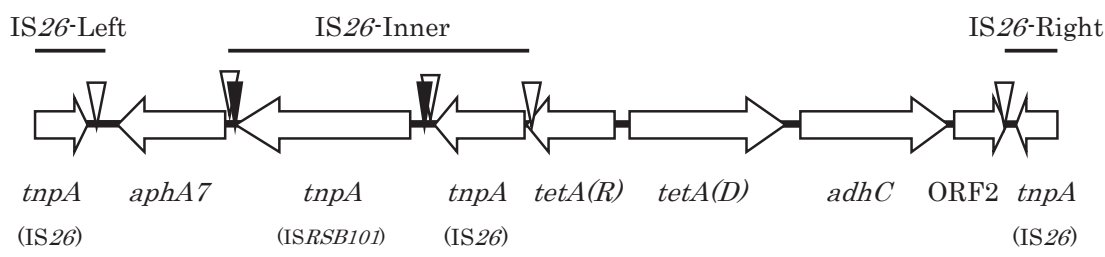

Photobacterium damselae pP99-018 (99.9\%)

Salmonella serovar Ordnez $(99.8 \%)$

Aeromonas punctata pFBAOT6 (100\%)

pTCKM3 (in this study)
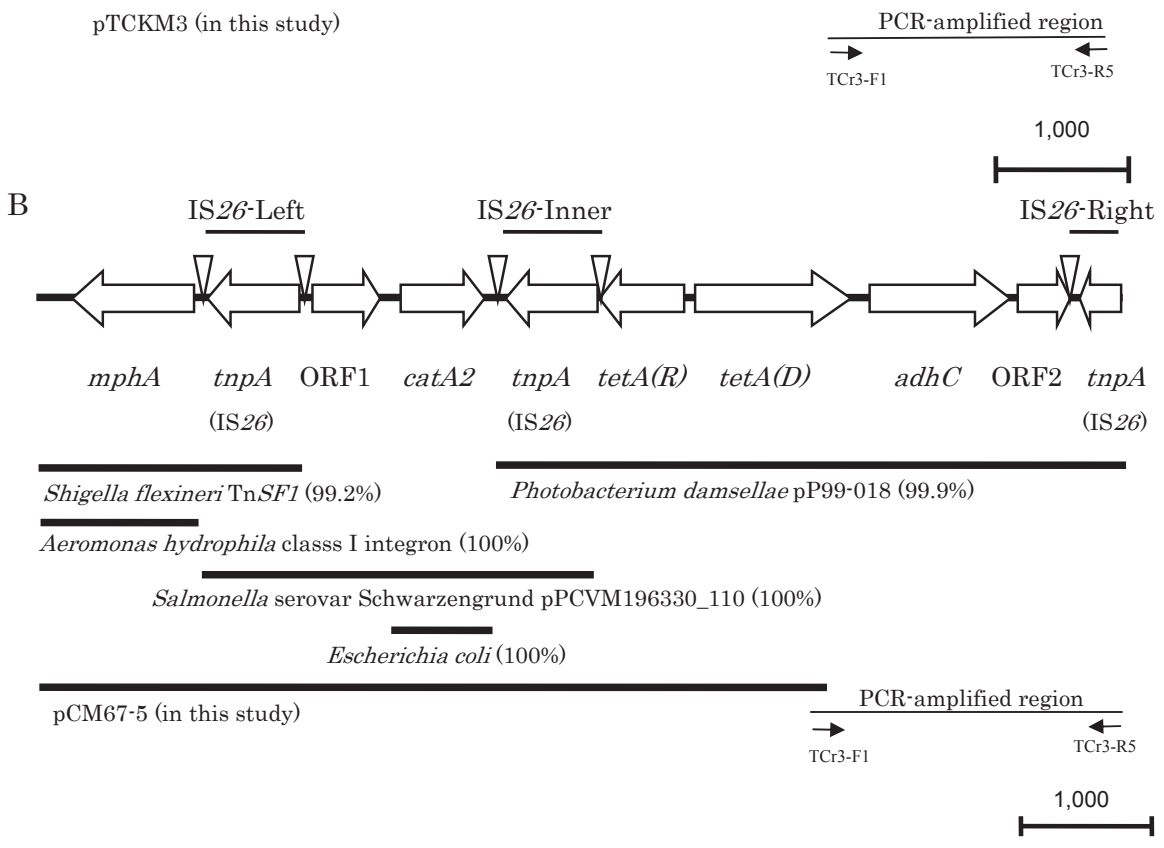

FIG. 2. Structures of the tetA $(D)$-surrounding region. (A) The structure found in Citrobacter sp. TA3 (pTCKM3). Solid bars indicate the regions which exhibit homology to the reported sequences; pP99-018 from Photobacterium damselae (Kim et al., 2008; Kim and Aoki, 1994), Salmonella serovar Ordnez (Allard et al., 1993), and pFBAOT6 from Aeromonas punctata (Rhodes et al., 2004). (B) The structure found in Salmonella sp. TC67 (pCM67-5). Solid bars indicate the regions which exhibit homology to the reported sequences; pP99-018 from Photobacterium damselae (Kim et al., 2008; Kim and Aoki, 1994), class I integron from Aeromonas hydrophila (Poole et al., 2006), TnSF1 form Shigella flexneri (accession no. AF188331), pPCVM196330_110 from Salmonella serovar Schwarzenground (accession no. CP001125), and Escherichia coli (Murray et al., 1990). Open inverted triangles represent IR of IS26 and closed ones represent IR of ISRSB101. 
shown in Fig.1. The hybridization patterns of the plasmids of Citrobacter sp. strains TA3 and TA6 and Alteromonas sp. TA55, which were isolated from fish farm A, were identical to each other, but different from that of Salmonella sp. TC67 from fish farm C. Although the plasmid of Citrobacter sp. TA3 was different from the other two in the digestion pattern, the difference may be due to the presence of two plasmids in TA3, since several DNA bands were shared by the three strains.

To determine the sequence of the $\operatorname{tet} A(D)$ region, plasmid pTA3 of Citrobacter sp. TA3 was digested with Sau3Al, and then fragments of 5 to $20 \mathrm{kbp}$ were ligated into the BamHI site of pUC18. The ligation mixture was electroporated into E. coli $\mathrm{DH} 5 \mathrm{a}$ and plated on LB medium supplemented with X-Gal $(0.05 \mu \mathrm{g} / \mathrm{ml})$, ampicillin $(50 \mu \mathrm{g} / \mathrm{ml})$ and chloramphenicol $(20 \mu \mathrm{g} / \mathrm{ml})$. The clone, pTCKM3 with a 5.8-kbp insertion, contained IS26-Left, the kanamycin resistance gene aphA7, an IS26-Inner disrupted with the insertion of ISRSB101, $\operatorname{tet} A(R)$ and tet $A(D)$, in this order (Fig.2A).

As reported by Allard et al. (1993), the 3' prime region of tet $A(R)$, a tet $A(D)$ repressor gene, is extended into the adjacent IS26. PCR with a set of primers TCr3F1 (5'-AGCCTGACCAATCTGAC-3') and TCr3-R5 (5'-GTGAAGAAGTGGCAGATC-3') described in Fig.2, and TA3 as a template DNA indicated the presence of adhC and ORF2, and IS26-Right in opposite orientation to the IS26-Left (Fig.2A). The flanking region by IS26Left and-Right was identical to the structure found in Photobacterium damselae (Kim et al., 2008; Kim and Aoki, 1994) except for the ISRSB101. The inserted ISRSB101 was $100 \%$ identical to that of plasmid pFBOAT6 of Aeromonas punctata (Rhodes et al., 2004), and was bordered by direct repeats of 9 nucleotide (5'-TGTTGCAAA-3') originating from IS26-Inner. By nucleotide sequencing of PCR-amplified products, we confirmed the presence of the same structures in Citrobacter sp. TA6 and Alteromonas sp. TA55.

A tet $A(D)$-containing clone, pCM67-5 conferring resistance to chloramphenicol, was isolated from the plasmid of Salmonella sp. TC67, which was isolated from fish farm C. A 6.0-kbp insert in the clone (Fig.2B) consisted of an erythromycin-resistance gene $m p h A$, IS26-Left, ORF1, the chloramphenicol-resistance gene catA2, IS26-Inner and tet $A(R)$ and tet $A(D)$. PCR with TCr3-F1 and TCr3-R5 also indicated the presence of adhC and ORF2, and IS26-Right. The genes from ORF1 to ORF2 were flanked by two IS26s in direct orientation. The structure from IS26-Inner to IS26-Right was identical to those of TA3, 6 and TA55 except for the absence of ISRSB101 within IS26-Inner. The IS26-Left in the opposite orientation and aphA7 in TA3 was replaced by $m p h A$, IS26-Left in direct orientation, ORF1 and catA2 in TC67. The sequence of $m p h A$ was $100 \%$ identical to that of Aeromonas hydrophila (Poole et al., 2006), and catA2 was $100 \%$ identical to that of Salmonella serovar Schwarzenground and E. coli (Murray et al., 1990).

The presence of $100 \%$ sequence identity found in the resistance gene regions of the three strains of the two genera, Citrobacter and Alteromonas, isolated from fish farm A cannot be explained by any vertical gene transfer in hereditary lineage. The only possible explanation is horizontal gene transfer, since conjugative plasmids can be transferred across different genera when no distance barrier exists. Horizontal gene transfer in the environment has been suggested by the structure homologies of mobile genetic elements and antibiotic resistance genes (Hartman et al., 2003; Heuer et al., 2009; Oppegaard et al., 2001). Geographic isolation of fish farm C from A (approx. $180 \mathrm{~km}$ ) seems to be relevant in the difference in the downstream region of tetA $(D)$.

The nucleotide sequences determined in this study have been deposited in the GenBank database under accession numbers AB262967 to AB262968.

\section{REFERENCES}

Allard, J. D., Gibson, M. L., Vu, L. H., Nguyen, T. T., and Bertrand, K. P. (1993) Nucleotide sequence of class D tetracycline resistance genes from Salmonella ordonez. Mol. Gen. Genet., 237, 301-305.

Chalmers, R., Sewitz, S., Lipkow, K., and Crellin, P. (2000) Complete nucleotide sequence of Tn10. J. Bacteriol., 182, 2970-2972.

Dahlberg, C., Linberg, C., Torsvik, V. L., and Hermansson, M. (1997) Conjugative plasmids isolated from bacteria in marine environments show various degrees of homology to each other and are not closely related to well-characterized plasmids. Appl. Environ. Microbiol., 63, 4692-4697.

Dahlberg, C., Bergström, M., and Hermansson, M. (1998) In situ detection of high levels of horizontal plasmid transfer in marine bacterial communities. Appl. Environ. Microbiol., 64, 2670-2675.

Furushita, M., Shiba, T., Maeda, T., Yahata, M., Kaneoka, A., Takahashi, Y., Torii, K., Hasegawa, T., and Ohta, M. (2003) Similarity of tetracycline resistance genes isolated from fish farm bacteria to those from clinical isolates. Appl. Environ. Microbiol., 69, 5336-5342.

Furushita M., Akagi, H., Kaneoka, A., Awamura, K., Maeda, T., Ohta, M., and Shiba, T. (2011) Structural variation of Tn10 that carries tetB found in fish farm bacteria. Microbes Environ., 26, 84-87.

Hartman, A. B., Essiet, I. I., Isenbarger, D. W., and Lindler, L. E. (2003) Epidemiology of tetracycline resistance determinants in Shigella spp. and enteroinvasive Escherichia coli: characterization and dissemination of tet $(A)-1 . J$ Clin Microbiol., 41, 1023-1032.

Heuer, O. E., Kruse, H., Grave, K., Collignon, P., Karunasagar, I., and Angulo, F. J. (2009) Human health consequences of use of antimicrobial agents in aquaculture. Clin. Infect. Dis., 49, 1248-1253.

Kado, C. I., and Liu, S. T. (1981) Rapid procedure for detection and isolation of large and small plasmids. J. Bacteriol. 
145, 1365-1373.

Kim, E. H., and Aoki, T. (1993) Drug resistance and broad geographical distribution of identical $R$ plasmids of Pasteurella piscicida isolated from cultured yellowtail in Japan. Microbiol. Immunol., 37, 103-109.

Kim, M. J., Hirono, I., Kurokawa, K., Maki, T., Hawke, J., Kondo, H., Santos, M. D., and Aoki, T. (2008) Complete DNA sequence and analysis of the transferable multiple-drug resistance plasmids ( $R$ Plasmids) from Photobacterium damselae subsp. piscicida isolates collected in Japan and the United States. Antimicrob. Agents Chemother., 52, 606611.

Kim, E. H., and Aoki, T. (1994) The transposon-like structure of IS26-tetracycline, and kanamycin resistance determinant derived from transferable $\mathrm{R}$ plasmid of fish pathogen, Pasteurella piscicida. Microbiol. Immunol., 38, 31-38.

Murray, I. A., Martinez-Suarez, J. V., Close, T. J., and Shaw, W. V. (1990) Nucleotide sequences of genes encoding the type II chloramphenicol acetyltransferases of Escherichia coli and Haemophilus influenzae, which are sensitive to inhibition by thiol-reactive reagents. Biochem. J., 272, 505510.

Oppegaard, H., Steinum, T. M., and Wasteson, Y. (2001) Horizontal transfer of a multi-drug resistance plasmid between coliform bacteria of human and bovine origin in a farm environment. Appl. Environ. Microbiol., 67, 3732-
3734.

Poole, T. L., Callaway, T. R., Bischoff, K. M., Warnes, C. E., and Nisbet, D. J. (2006) Macrolide inactivation gene cluster mphA-mrx-mphR adjacent to a class 1 integron in Aeromonas hydrophila isolated from a diarrhoeic pig in Oklahoma. J. Antimicrob. Chemother., 57, 31-38.

Rhodes, G., Huys, G., Swings, J., McGann, P., Hiney, M., Smith, P., and Pickup, R. W. (2000) Distribution of oxytetracycline resistance plasmids between aeromonads in hospital and aquaculture environments: implication of Tn1721 in dissemination of the tetracycline resistance determinant tetA. Appl. Environ. Microbiol., 66, 3883-3890. Rhodes, G., Parkhill, J., Bird, C., Ambrose, K., Jones, M. C., Huys, G., Swings, J., and Pickup, R. W. (2004) Complete nucleotide sequence of the conjugative tetracycline resistance plasmid pFBAOT6, a member of a group of IncU plasmids with global ubiquity. Appl. Environ. Microbiol., 70, 74977510.

Sandaa, R. A., and Enger, Ø. (1994) Transfer in marine sediments of the naturally occurring plasmid pRAS1 encoding multiple antibiotic resistance. Appl. Environ. Microbiol., 60, 42344238.

Yano, K., and Nishi, T. (1980) pKJ1, a naturally occurring conjugative plasmid coding for toluene degradation and resistance to streptomycin and sulfonamides. J. Bacteriol., 143, 552-560. 